\title{
Affective field during collaborative problem posing and problem solving: a case study
}

\author{
Maike Schindler ${ }^{1,2}$ (D) Arthur Bakker ${ }^{3}$
}

Published online: 2 September 2020

(C) The Author(s) 2020

\begin{abstract}
Educators in mathematics have long been concerned about students' motivation, anxiety, and other affective characteristics. Typically, research into affect focuses on one theoretical construct (e.g., emotion, motivation, beliefs, or interest). However, we introduce the term affective field to account for a person's various affective factors (emotions, attitudes, etc.) in their intraplay. In a case study, we use data from an extracurricular, inquiry-oriented collaborative problem posing and problem solving (PP\&PS) program, which took place as a 1-year project with four upper secondary school students in Sweden (aged 16-18). We investigated the affective field of one student, Anna, in its social and dynamic nature. The question addressed in this context is: In what ways does an affective field of a student engaging in PP\&PS evolve, and what may be explanations for this evolvement? Anna's affective field was dynamic over the course of the program. Her initial anxiety during the PP\&PS program was rooted in her prior affective field about mathematics activities, but group collaboration, the feeling of safety and appreciation, together with an increased interest in within-solution PP and openness for trying new things went hand in hand with positive dynamics in her affective field.
\end{abstract}

Keywords Affect $\cdot$ Affective field $\cdot$ Problem posing $\cdot$ Problem solving

Electronic supplementary material The online version of this article (https://doi.org/10.1007/s10649-02009973-0) contains supplementary material, which is available to authorized users.

\section{Maike Schindler}

maike.schindler@uni-koeln.de

1 Örebro University, Örebro, Sweden

2 Present address: University of Cologne, Cologne, Germany

3 Utrecht University, Utrecht, the Netherlands 


\section{Introduction}

This article introduces the notion of "affective field" to denote the complex of students' emotions, attitudes, interests, beliefs, etc. that are at stake during activity. We propose this notion as a way to compensate for the dominant trend to treat each affective construct in its own separate body of literature (as observed, e.g., by Hannula, 2011; Renninger \& Hidi, 2016). We have chosen the field metaphor because of the parallel we see with magnetic fields. First, magnetic fields have positive and negative poles, just like the attractions and repulsions that are typical of affect. Second, fields tend to be open, not purely tied to one body, as affective factors can spread across groups (de Freitas, Ferrara, \& Ferrari, 2019). Third, the field metaphor allows us to talk about bundles of affective factors involved in learning activity such as mathematical problem solving and problem posing (the topic of this special issue).

Affect is an important part of mathematical activity (e.g., of mathematical problem solving) and a relevant predictor for students' future mathematical behavior (Hannula, 2019). Because of common phenomena such as disengagement and diminishing participation, affect has been of interest for mathematics educators for many years (Grootenboer \& Marshman, 2016). Accordingly, it has been of increasing interest to researchers in mathematics education over the last decades (see, e.g., the Special Issue on affect in Educational Studies in Mathematics, Zan, Brown, Evans, \& Hannula, 2006; see also Batchelor, Torbeyns, \& Verschaffel, 2019; Schukajlow, Rakoczy, \& Pekrun, 2017). It involves a variety of factors or constructs such as emotions, attitudes, beliefs, values, motivation, interest, and many more (e.g., Grootenboer \& Marshman, 2016; McLeod, 1992), which are related to one another (O'Keefe, Horberg, \& Plante, 2017).

Scholars such as Hannula (2002) and Cobb et al. (1989) have shown how students' affect is better viewed more holistically and dynamically. These studies, which investigated students' affect during problem solving-focused teaching experiments over a period of time, were an inspiration and starting point for this study. Yet, as observed by Renninger and Hidi (2016), most research still atomistically studies (single) affective constructs in variables and seeks to identify relationships between them as if they are separate entities.

Problem solving (PS) has close connections with problem posing (PP)—generating new problems or reformulating given ones (Silver, 1994). PP is emphasized as important by many scholars (e.g., Cai et al., 2015; Silver, 1994; Singer, Ellerton \& Cai, 2013) and has an inherent role in students' PS especially in inquiry-based or open-ended learning approaches, where students inquire into mathematical problems, set their own goals, and pursue them (Bonotto \& Dal Santo, 2015; Cai \& Cifarelli, 2005; Cifarelli \& Cai, 2005; Cifarelli \& Sevim, 2015; Kilpatrick, 2016; Silver, 1994). PP within PS is associated with improvement of students' PS skills, their understanding of mathematical concepts, and, furthermore, students' attitudes, motivation, and self-confidence (Cai \& Cifarelli, 2005; Chang et al., 2012; Chen, Van Dooren, \& Verschaffel, 2015; Cifarelli \& Sevim, 2015; Silver, 1994; Silver \& Cai, 1996; Singer \& Moscovici, 2008). However, research explicitly addressing students' affect in its dynamics during PP\&PS is scarce: Whereas the dynamics of students' affective factors in PS programs have been investigated in selected studies (e.g., Cobb et al., 1989), this is hardly the case for programs involving both PP and PS (see, e.g., Cifarelli \& Sevim, 2015, for an exception).

The purpose of our article is to analyze an affective field's emergence and dynamics in entanglement with PS\&PP activities, with PP in particular. We use the case of the affective field of a Swedish upper secondary school student, Anna, who took part in an extracurricular mathematics project where four students (aged 16-18) met and collaborated in inquiryoriented meetings. We chose to focus on Anna, since her affective development was the most 
dramatic, and hence the most interesting, and because she was open talking about her feelings, which allowed us to study the dynamics of her affective field. We trace the changes in her affective field over the course of an inquiry-oriented PP\&PS program. Based on previous research on affect (e.g., Carmichael, Callingham, \& Watt, 2017; Cobb et al., 1989; Grootenboer \& Marshman, 2016; Hannula, 2002; Roth \& Walshaw, 2019), we assume that various affective factors (emotions, attitudes, etc.) simultaneously play a role when students engage with mathematical PS and in PP-which we keep in vision through the use of the notion of affective field. Given the scarcity of research on affect during PP\&PS, we are interested in how her affective field may evolve over time. We ask the research question: In what ways does an affective field of a student engaging in PP\&PS evolve, and what may be explanations for this evolvement?

\section{Problem posing and problem solving during students' mathematical inquiry}

Problem posing (PP) is an important activity for school students. In recent years, the potential of integrating PP in classroom practices has been supported both theoretically and empirically (Cai et al., 2015; Singer, Ellerton, \& Cai, 2013). PP is associated to improvement of students' PS skills, their understanding of mathematical concepts, and to students' attitudes, motivation, and selfconfidence (Cai \& Cifarelli, 2005; Cifarelli \& Sevim, 2015; Silver, 1994; Silver \& Cai, 1996; Singer \& Moscovici, 2008).

PP is regarded as essential in mathematical thinking (Bonotto \& Dal Santo, 2015) and "as a critically important intellectual activity in scientific investigation" (Cai et al., 2015, p. 5). However, there is no consensus on a definition of the term PP (Singer et al., 2013). In our work, we focus on PP during PS (Silver, 1994), so-called within-solution problem posing (Cifarelli \& Sevim, 2015, p. 177). Within-solution PP happens when a student changes the goal and conditions of a problem intentionally, or shifts perspective, for instance, in inquiry-based learning approaches. In students' PS, there can even be "series of self-generated problematic situations within which particular goals and purposes are pursued" (Cifarelli \& Sevim, 2015, p. 180), for instance, when students generalize or broaden the scope of mathematical problems (see also Silver, 1994).

The inherent role of PP within PS has been acknowledged and emphasized in research (e.g., Pirie \& Kieran, 1994; Schoenfeld, 1985; Silver, 1994) as well as in education: For instance, the NCTM Standards (2000) recommend for students to formulate problems themselves, to put up and investigate conjectures, and to generalize and extend problems. Investigating the interplay of PP and PS in students' exploration, Cai and Cifarelli (2005; Cifarelli \& Cai, 2005) found the relation between PP and PS to be recursive, involving "problem posing-solving chains" (p. 62), where PS and PP may alternate and coevolve. Based on such observations, we use the term PP\&PS approaches for PS approaches that open up for within-solution PP and provide opportunities for students to pursue their own goals, shift perspectives, and follow their PP interests.

We lean on previous research that has used open-ended problems, inquiry-based learning approaches, and modeling problems (see Cifarelli \& Cai, 2005; Hansen \& Hana, 2015; Kilpatrick, 2016). A common feature of such approaches is that students inquire into mathematically rich situations or problems, which naturally also involves PP activities (Bonotto \& Dal Santo, 2015; Cifarelli \& Sevim, 2015; Kilpatrick, 2016; Silver, 1994): Students set their own goals and pose problems to themselves that do not necessarily have to be difficult but may even be shifts in perspective and attention (Bonotto \& Dal Santo, 2015; Starko, 2010). 
Several scholars (e.g., Brown \& Walter, 1993; Cifarelli \& Sevim, 2005) have pointed out the potential benefits of within-solution PP, including conceptual growth through in-depth inquiry into the problem and increased PS through PP. For instance, Cifarelli and Sevim (2015) illustrated how the coevolving process of PP and PS increased the level of generalization, broadened perspective, and expanded the scope of the problem, which led to conceptual progress.

Researchers have wondered whether inquiry-driven PP\&PS can have a positive influence on students' affect or vice versa or perhaps both. Cifarelli and Sevim (2015), in a case study on fourth graders, found that " $[\mathrm{t}]$ he students were highly motivated to answer questions that arose from their sense of surprise in their results" (p. 188) and that the increased motivation went along with an "ongoing sense of accomplishment" (p. 188), which in turn may be related to students' self-efficacy. Chen et al. (2015) investigated a training program aiming to enhance fourth grade students' PP\&PS abilities, and, through using questionnaires, they showed that not only the originality of the posed problems but also students' PP\&PS beliefs were affected positively. Chang et al. (2012) found that a PP\&PS training program increased students' flow experiences, which “could augment students' motivation and learning process" (p. 776). Further, PP in students' inquiry may influence students' attitudes towards mathematics positively (e.g., Brown \& Walter, 1993; see Silver, 1994, for an overview). On the other hand, PP may also have a negative influence on students' affect: Silver (1994) hypothesizes that especially students with a history of success in regular, non-inquiry-based teaching with direct instruction may have little desire or motivation to be engaged in PP activities. Finally, we think that the distinctions between affect and PP are analytic distinctions of a much more fluid and complex phenomenon. We prefer to think in terms of co-occurring phenomena rather than (in)dependent variables (cf. Barad, 2007).

\section{Affective field}

Affect is a complex phenomenon with many factors involved (e.g., Hannula, 2019), while the terminology and concepts used to account for factors of affect are partially used interchangeably with varying meanings (Lomas, Grootenboer, \& Attard, 2012). In the following, we describe our theorization of students' affect as affective field, which means the bundles of affective factors involved in particular situations in their intraplay. In doing so, we lean on McLeod's (1992) seminal conceptualization of the affective domain, which includes emotions, attitudes, and beliefs. However, whereas we see that McLeod refers to a conceptual domain when he writes about the affective domain (note the terms reconceptualizing and concepts), our notion of affective field rather refers to the affective factors at work in people and groups of people.

Research into affect typically focuses on one theoretical construct (e.g., emotion, motivation, beliefs, interest). In our article, we take a holistic view on the affective domain: We argue that there is an added value in treating affect as a field to counteract the fragmented literature on a multitude of affective constructs and build on approaches assuming that emotions, interest, motivation, and engagement are highly related constructs (Hannula, 2006, 2011; O'Keefe et al., 2017; Renninger \& Hidi, 2016) and we are inspired by, among others, Hannula's (2002) and Cobb et al.'s (1989) holistic theorizations of affect.

In accordance with the increased acknowledgment of the sociocultural context in research on affect (e.g., Grootenboer \& Marshman, 2016; Heyd-Metzuyanim et al., 2016; Middleton et al., 2016; Pantziara, 2016), we assume affective factors of participants in the social context to interact and to be hardly separable from one another. For instance, if three students in a group work are 
highly motivated and enjoying it, this positive affect is likely to have an impact on the fourth student (for instance, motivating him/her) (see de Freitas et al., 2019 for affectivity). Also, the norms within these contexts interact with affective fields (Cobb et al., 1989).

In our theorization of affect, we take a holistic stance since we are talking about the affective field as a fluid phenomenon. Constructs such as emotions and beliefs have the advantages of communication and research, but their self-sustained essences "constitute a rather shaky ground" (Sfard, 2008, p. 56), and objectifying talk can lead to controversies about the correctness, even though there is no real right or wrong-leading to an "ontological collapse" (p. 57) of taking statements about discourse to be about the extradiscursive world. Yet, for research, it is important to have concepts to grasp the phenomena under investigation. Therefore, despite our holistic stance, we investigate the affective field (taken as a whole) through researching bundles of factors. Table 1 presents working definitions of some affective factors that are important for describing students' affective field in this article. These comprise

Table 1 Factors involved in students' affective field

\begin{tabular}{|c|c|c|}
\hline $\begin{array}{l}\text { Affective } \\
\text { construct }\end{array}$ & Working definition & $\begin{array}{l}\text { Example } \\
\text { (from our data) }\end{array}$ \\
\hline Emotions & $\begin{array}{l}\text { Emotions are feelings such as happiness, fear, or } \\
\text { anger in a particular situation that are temporary } \\
\text { and unstable (Emotion, n.d.; Grootenboer \& } \\
\text { Marshman, 2016; McLeod, 1992) }\end{array}$ & "It's fun!" \\
\hline Attitudes & $\begin{array}{l}\text { Attitudes are stabilized affective responses within } \\
\text { certain situations or rather a psychological } \\
\text { tendency towards an object or entity } \\
\text { (Grootenboer \& Marshman, 2016; McLeod, } \\
\text { 1992; Savelsbergh et al., 2016) }\end{array}$ & "I am always afraid of being wrong." \\
\hline Beliefs & $\begin{array}{l}\text { Beliefs are students' views of some aspect of the } \\
\text { world (Philipp, 2007), e.g., beliefs about } \\
\text { mathematics and beliefs about problem solving }\end{array}$ & $\begin{array}{l}\text { "We just want to know what the answer is. } \\
\text { It's not how we solve it, it's if we get the } \\
\text { right answer." }\end{array}$ \\
\hline Self-efficacy & $\begin{array}{l}\text { Self-efficacy is a student's own } \\
\text { assessment/judgment of her capabilities to ex- } \\
\text { ecute specific behaviors in specific situations, } \\
\text { e.g., to pose and solve math problems (Pajares } \\
\text { \& Miller, 1994) }\end{array}$ & $\begin{array}{l}\text { "I felt like I cannot do this." } \\
\text { "It kind of affects me when I cannot solve it. I } \\
\text { do not feel very confident and strong." }\end{array}$ \\
\hline $\begin{array}{l}\text { Interest and } \\
\text { motiva- } \\
\text { tion }\end{array}$ & $\begin{array}{l}\text { Interest is a preferred engagement of a person } \\
\text { (student) with a certain entity, which can be } \\
\text { more or less situational (e.g., finding a problem } \\
\text { appealing) or enduring (e.g., general interest in } \\
\text { math)-it is a continuum (Akkerman, } \\
\text { Vulperhorst, \& Akkerman, 2019; Renninger, } \\
\text { 2009; Schukajlow et al., 2017) } \\
\text { Motivation is the ensemble of reasons and } \\
\text { influences why students engage in any pursuit, } \\
\text { e.g., in mathematical problem solving, or in a } \\
\text { particular approach (see Middleton, Jansen, \& } \\
\text { Goldin, 2016; Motivation, n.d.) }\end{array}$ & $\begin{array}{l}\text { "We would like to see!" (a student referring } \\
\text { to another student's approach) } \\
\text { "And (...) then you wanna do it. Because it's } \\
\text { a challenge." }\end{array}$ \\
\hline Values & $\begin{array}{l}\text { Value is the appreciation or perceived importance } \\
\text { of objects, contents, and actions (see Rokeach, } \\
\text { 1973; Schukajlow et al., 2012) }\end{array}$ & $\begin{array}{l}\text { "That's good. (...) It's logical." (a student } \\
\text { referring to another student's approach) }\end{array}$ \\
\hline
\end{tabular}


emotions, attitudes, beliefs, self-efficacy, motivation, interest, and values. We use working definitions because generally shared definitions do not exist (see Grootenboer \& Marshman, 2016; Hannula, 2019). Of course, for these working definitions, we needed to make decisions: Although some scholars would, for example, consider interest to be an emotion, we follow Renninger and Hidi (2016) to regard interest to be emotionally charged, but not to be an emotion itself. Also, we have decided to take values as analytically distinguishable from interest, following Schukajlow et al. (2012), even though others might see them in unity.

\section{This study}

This article presents a post hoc analysis of the affective field of a student, Anna, when engaging in PP\&PS and its evolvement in an extracurricular inquiry-oriented project. It was in hindsight that we realized how affect was a crucial aspect in students' PP\&PS. We saw the potential of the data to illustrate the fluidity and multiplicity of Anna's affective field in entanglement with her PS\&PP activities, with PP in particular.

\subsection{The Creative Math Meetings}

The so-called Creative Math Meetings (CMMs) was a program developed at Örebro University, Sweden, in particular by the first author of this article, in collaboration with a local school. It took place roughly every other week during a full school year, spanning from August to May. The university invited students from a local school to participate. The CMMs addressed upper secondary school students, aged 16 to 18 . Participation in the CMMs was voluntary. Prior to the CMMs, the university teacher held a talk at the school with the purpose to recruit interested students to join the CMMs. The CMMs were announced as a learning and research project aiming to develop mathematical activities for interested students with a focus on students' creative problem solving.

During the CMMs, the students worked on different mathematics problems, which often came without explicit instruction what to inquire about. The students were not asked explicitly to also pose problems - rather we aimed for self-driven within-solution PP by the students, as described in Section 2. In those meetings in focus in this article (see Fig. 1), the students (1) were encouraged to find different solutions for a particular geometry multiple solution task (Leikin, 2009; Novotná, 2017) in meeting 1, (2) were asked to work on a problem where they tested whether one can lay down domino tiles (displaying the numbers 0-6 and 0-9) in a circle in meeting 2 (Kießwetter \& Rehlich, 2005), and (3) worked on a problem where they were supposed to inquire into round

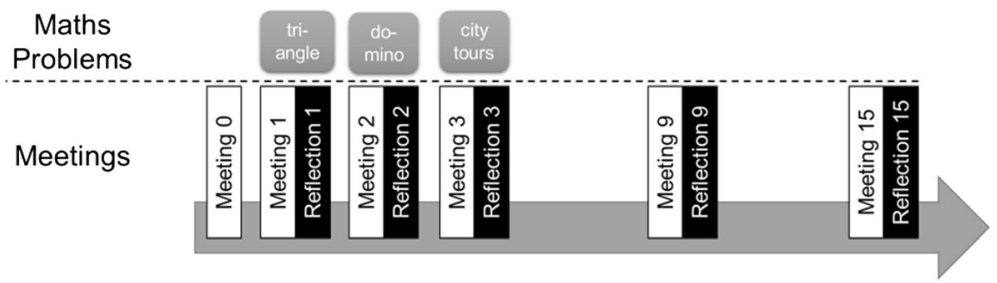

\section{One School Year}

Fig. 1 Creative Math Meetings and data used in this article (M1, M2, M3, M9) 
tours in a city map (Eulerian graphs) in meeting 3 (see Supplementary Materials 1, 2, and 3 for a description of the problems and on how they each afforded PP).

In the meetings, the students used to first work on the problems individually for a short time (ca. $15 \mathrm{~min}$ ) and then worked in groups for most of the time (ca. $60 \mathrm{~min}$ ). At the end of each meeting (except M0), reflections took place: These reflections were minimally guided: The students reported - in their own words - how it went, about their group work, and their discoveries. The reflections took approximately 20-30 min each. In these reflections, the students were not explicitly asked to report about their affect, for example, on their emotions and self-efficacy, since it was not the program's original aim to investigate student affect. However, very early, it became clear that the PP\&PS was an affective experience for the students, and they - especially Anna - reported much about their anxieties, pride, or other emotions. All in all, the project comprised 15 meetings (Fig. 1).

\subsection{The group}

Over the course of the first CMMs, a stable group of four students attended the CMMs regularly: Anna and David, two 18-year-old students in Swedish upper secondary grade 3 (grade 12 in the K-12 system), and Jakob and Linda, 16-year-old students in grade 1 (grade 10, all names are pseudonyms). In this project, the first author of this paper was the teacher. This was because the school teachers were not used to an inquiry-oriented collaborative PP\&PS approach towards teaching and wanted to sit in on and get to know the program. Two school teachers attended the CMMs irregularly as observers. The teacher in the CMMs had 5 years of experience as a school teacher and had furthermore taught for 6 years at a university level in teacher education programs before this project. In the CMMS, the students talked in English fluently: They were partially used to do so in their international program at school (English as teaching language: Anna, Jakob, and Linda), had been on longer exchange programs to English-speaking countries, or were raised bilingually (Swedish-English).

This case study focuses on one out of the four students: Anna. Her affective development was the most dramatic: There was an incident in the first meeting, only with Anna (not the rest of the group) where she told the teacher individually that she could not bear the feeling of being unable to solve the problem and wanted to quit the program. Yet, during the project, her view on mathematics and her affective field changed substantially. Furthermore, it was not the project's original aim to inquire into the affective factors involved in PS\&PP, and the students were not explicitly encouraged to talk about their feelings. Yet, Anna's openness allowed us to trace her affective field as analytic case.

\subsection{Data and data analysis}

All meetings (except for M0, which was a getting-to-know-each-other meeting) were video recorded with one or two cameras. Inspired by the studies of Hannula (2002) and Cobb et al. (1989), we intended to let the data speak when analyzing our data - in line with the idea of affective field: We used the case of what we conceptualized as Anna's affective field during PP\&PS as "inspiring narrative" (Hannula, 2002, p. 31), which is not created from a void but rather is extracted from episodes observed during the meetings as well as from the stories the students told in their reflections. To trace the dynamics of Anna's affective field, we used the data from the group reflections of the meetings, where the students described their emotions, attitudes, or beliefs related to PP\&PS. In particular, the reflections in meetings 2 and 3 were 
significant with respect to students' affect and are in focus. In the transcripts, we coded all affective factors related to students' PP\&PS that came up. For example, when Anna uttered 'I am always afraid of being wrong," we paraphrased this as "anxiety of being wrong" and coded it as an attitude (see Table 1 for a list of all factors that were coded). We did so for all students: This was because we did not want to cut out and isolate Anna's PP and her affect from the group's but to take into account the social nature of PS\&PP and of affect.

Note that in the coding process, we decided to code interest and motivation together, since intrinsic motivation and interest are partially considered similar (Wigfield \& Cambria, 2010) and they were practically difficult to separate in the coding of students' group work. Based on our codings, we created snapshots of students' affective fields (Figs. 3, 5, 6, and 7): Overviews with bundles of beliefs, attitudes, etc. as described by the students (mostly paraphrased).

For finding explanations for the dynamics in Anna's affective field, we also used data from later reflections (meeting 9) and from an important affective incident in the first meeting, when Anna initially wanted to quit the program because of her insecurity and anxiety related to the PP\&PS. Further, we used all group work data of the meetings 2 and 3 and coded and paraphrased the affective factors. To trace the factors in their fluidity, we captured them in "flow tables" (see Supplementary Materials 4 and 5), which are tables capturing students' group work, where the affective factors together with a paraphrase of the respective student's utterance (e.g., PP interest to find a proof, brought forward by Anna) were noted in the chronological order of appearance in the group work. These tables indicate the flow of affectivity connected to PS\&PP in the students' work. Based on these tables, we (a) report on the group work with focus on affect and PP as well as its major themes and (b) created snapshots of the affective field in the group work (structurally similar to the ones for the student reflections).

\section{The case of Anna's affective field}

To demonstrate dynamics in Anna's affective field, we use the same model (Fig. 2) in all following figures to elaborate on the affective factors entangled with PP\&PS. As to be expected, we did not find evidence of all factors in all situations under investigation. The boxes stay empty when aspects were not explicitly at stake.

Fig. 2 Affective factors

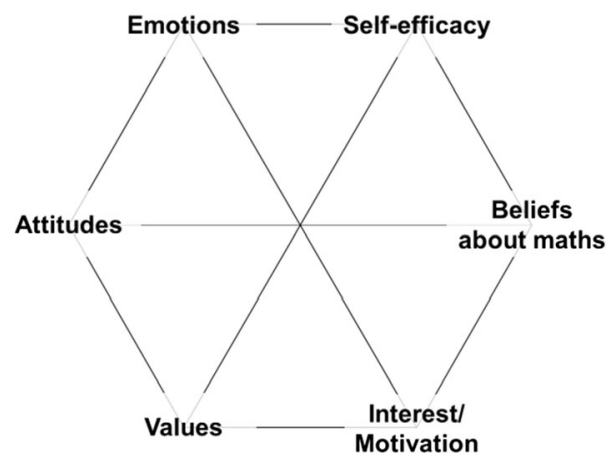




\subsection{Incident in first meeting: Anna's initial anxiety and students' prior affect}

We begin with an incident in meeting 1 in minute 106ff, where the students worked on a problem (a geometry multiple solution task, see Supplementary Material 1) that afforded PP in a way that the students were asked to find different solutions and perspectives. Anna took the opportunity to talk to the teacher who was passing by:

Anna: I'm not sure I will be coming back next time.

Teacher: Why not?

Anna: I don't know. It kind of affects me when I cannot solve it. I don't feel very confident and strong when I leave. So... I don't know. I don't get a good feeling here. So, I will have to think about it.

Teacher: Yes do so. (Inaudible) But research says the girls are not as self-confident as boys are. So, this should not be a reason. If I know that this is something... (inaudible) So I would strongly suggest that you come back. (inaudible)

Anna: Now it was also the same problems [referring to the geometry multiple solution task that they had already worked on in the prior getting-to-know-each-other meeting]. Maybe another problem is like more in my style. And maybe it's easier. And maybe this can be another thing to, like, motivate me. But I don't know. I'll have to think about it.

Teacher: But do so. (inaudible, referring to the next problem in the next session)

Anna: I'll think about it.

Teacher: Yes. Do so. Please.

Our interpretation is that Anna's experience of failure in PS came with an affective reaction. The fact that she could not solve the problem caused negative emotions ("I don't get a good feeling here") and appeared to address her self-efficacy (feeling "not strong," "it affects me," "I don't feel very confident and strong") (Fig. 3). The (female) teacher attributed Anna's low self-concept to gender differences and thus depersonalized the issue and tried to show empathy and to - in a certain waybond with Anna (in the sense of "we women should not be frightened and need to counter this difference"). Anna then hypothesized that the failure may be related to the type of mathematical problem: that other problems might be more "her style" and could "motivate her."

In the second meeting, Anna described the same incident in retrospect, stating "Yeah, I was... Yeah, I remember. I was, like, I can't do this, okay, crying (rubbing her eyes, laughing) (everybody laughing)." Jakob, in turn, added "I was expecting something extremely hard. I was, like, tense," which was affirmed by Linda. Anna's utterances reflect a low self-efficacy ("I can't do this") and helplessness/sadness ("crying"). Anna even mimicked to cry through rubbing her eyes and laughed - possibly because she was embarrassed that she had had bad feelings in the first place. In meeting 9, Anna detailed:

Because for me like in the beginning in the very, very first lesson we had that problem with a triangle. I was looking at it and I did not have a solution; I did not have an answer. That's why I didn't want to come back because I felt like I can't do this. (...) Because usually if I don't get the answer it's like, damn, I suck at this. Then you just want to quit. 


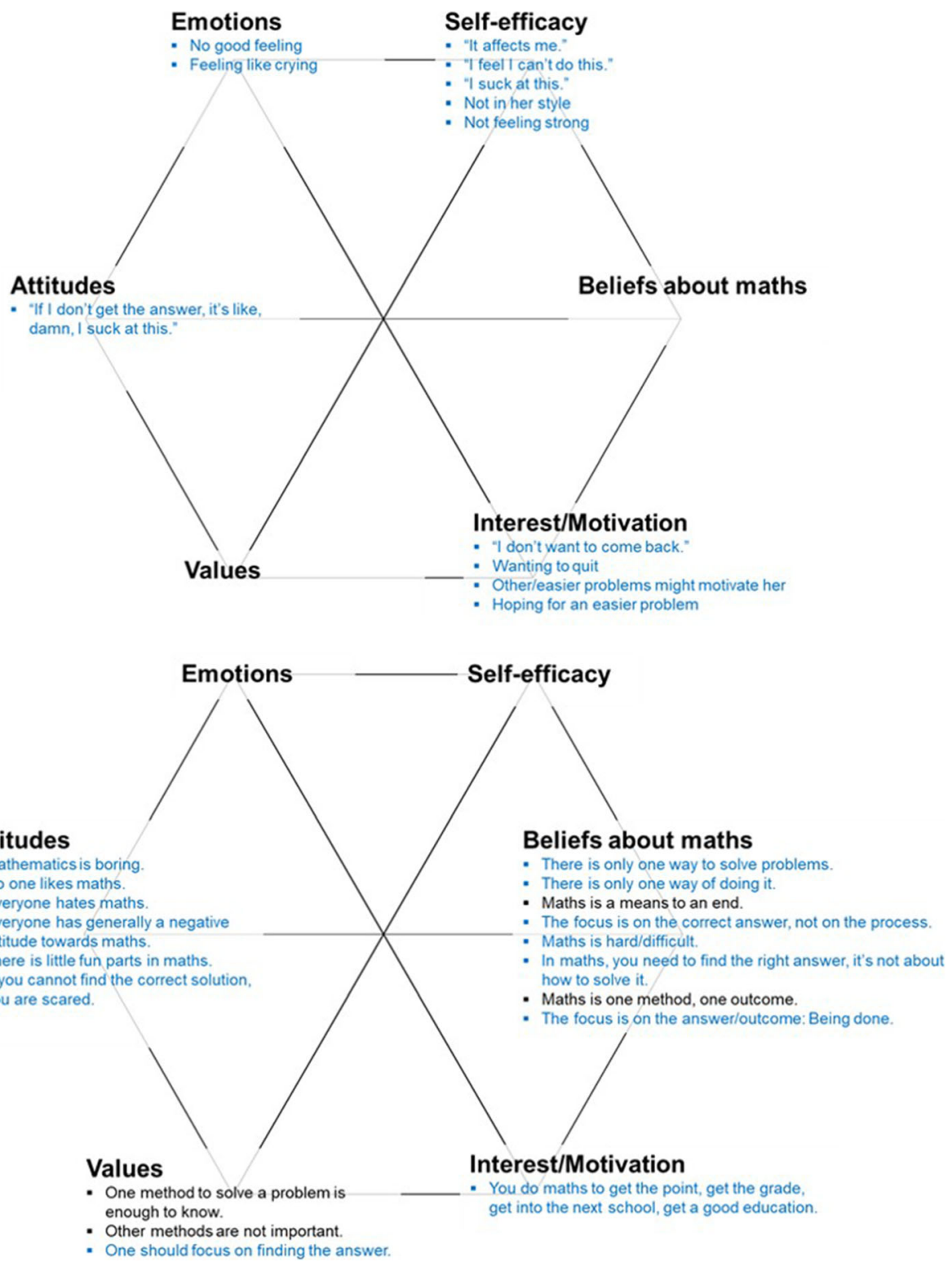

Fig. 3 Anna's affective field during 1st meeting (top) and students' affective field prior to the project (bottom) (blue entries relate to Anna)

The emotional experience of not being able to solve the problem caused avoidance strategies and affected her self-efficacy. Anna was a very good mathematics student at school. Her experience of discomfort in this "new" mathematical inquiry activity can be related to what Silver (1994) hypothesized: That PP\&PS may have a negative affective influence on students who have a history of success in regular, non-inquiry-based teaching. Most likely, Anna was not used to this kind of frustration in mathematics and maybe she wanted to protect herself 
from a decreased self-efficacy or from changing her mathematical identity (Horn, 2008; Kaspersen, Pepin, \& Sikko, 2017).

In retrospective reflections in meeting 9, David and Anna described their affect prior to the project. Their descriptions help to explain why Anna experienced anxiety and tenseness in the beginning of the project (see Fig. 3). For example, she believed that there is only one way to solve a problem and was generally scared when she did not find that particular way. The students' beliefs about mathematics and their values can be related to a typical non-inquiry based-teaching, the attitudes that they describe are predominantly negative (boredom, hatred, anxiety), and their motivation is extrinsic rather than intrinsic. In particular, the students were not used to within-solution PP in mathematics, finding different perspectives, or trying new things. In our interpretation, Anna's negative affective reaction - a repulsion - is connected to her unfamiliarity with PP\&PS approaches. We use the data from the following meetings to trace how Anna increasingly got acquainted to within-solution $\mathrm{PP}$ - together with positive dynamics in her affective field.

\subsection{Second meeting: PP interest and positive affect in group work}

In the second meeting, the students worked on a problem (the domino problem, see Supplementary Material 2) that afforded within-solution PP in a way that a trial-anderror approach hardly leads to a (quick) solution, which sets the stage for the students to inquire into regularities, patterns, and generalizations self-driven. After their individual work, the students were encouraged by the teacher to sit together and share their ideas with each other: "I would suggest that you present to each other your ideas. If you have not finished with your ideas, perhaps you can help each other out (...). Yeah?"

Group work: In the following, we will characterize the students' group work with regard to PP and affect. Jakob voluntarily started the group work by reporting about his individual failure experience in single work:

I was hoping for an epiphany (smiling). But that's never smart (all students laughing).

But I wasn't really sure where to go. So, I listed this, and ... then I gave up and desperately tried to make a circle (all students laughing).

This move by Jakob indicated his emotion in single work, where he resigned, and it transported a mathematics-related value, the acceptance of failure. In turn, Anna showed empathy and emotional support for him and the interest to include his idea even though it failed in the end ("Well, maybe we can find use for it [your approach] later?"). Jakob then showed interest in the other students' approaches ("Did someone solve this problem?"). Anna confirmed this, yet indicated insecurity ("I'd like to think I did it."), and Jakob decided that David, who was more confident, should go on ("Okay, so, confident guy goes first."). David then, reporting his approach, brought forward his PP interest: generalizing the particular mathematics problem to a general problem (about even and odd numbers). This PP focus also caught Anna's attention ("You said something earlier about even and odd numbers. Because..."), which deepened David's interest in generalization and made him interested to even find a proof. When David finished his explanations, Jakob turned again to Anna, asking: "You think you solved it as well?", indicating interest in her approach. Anna again showed hesitance 
("Yeah, I'd like to think I solved it."), but— this time — was encouraged by Jakob to talk about it ("We would like to see (smiling)."). Anna then, telling her approach, revealed that she also had had the PP interest to generalize the problem (to even and odd numbers). This was appreciated by the others as "logical" (Jakob), "sounds like it would work" (Jakob) and "it makes sense" (Linda). In turn, David showed interest to check whether the two approaches (by David and Anna) were compatible and combinable. This went along with a certain emotional arousal: First, there was tension, since David thought that their approaches were different. When Anna then explained and confirmed that they actually were compatible, David was relieved, first throwing his hands in his face with the other students observing him tensely (Fig. 4, left) - and then he started chuckling. This relief then spread among the group, together with happiness and joy, the students smiling and chuckling (Fig. 4, right) - and with Anna being in the center of the group, being empowered. In the following group work, Anna was being more proactive in suggesting what to do, bringing her PP interest more into play (e.g., suggesting to find a proof for the general solution and to combine the approaches by David and herself).

To summarize, we identified two major themes in the group work: The first theme was the creation of an atmosphere of safety and appreciation through students' handling of failure experiences and their interest in one another's ideas. Jakob, Linda, and Anna each reported, several times, about negative feelings during the individual work preceding the group work (insecurity/failure experience). Every time the students mentioned individual insecurity or failure experiences, the group comforted the respective student, showed emotional support, or showed interest in and appreciation for the approaches, despite the mistakes. The second theme was students' increasing establishment of norms about PS and interest in within-solution PP. In their PS, they, for instance, frequently mentioned their appreciation of logical, elegant, simple, fast, "sense-making," or "believable" approaches. The students also developed an increased interest in within-solution PP (e.g., Cifarelli \& Sevim, 2015), which was entangled with positive affect: In particular, they developed an interest to generalize the problem, to find a proof for their generalization, and to combine their solutions for such a proof, and they began to establish norms about what to strive for in open problem situations (generalizations, proofs, and combinations of their solutions). This can be related to Cifarelli and Sevim's (2015) descriptions of within-solution PP as "transformations of the original problem" (p. 178), which expands "the scope of the original problem" (p. 178). The PP of the students in our case study was accompanied by happiness, relief, and appreciation when the students found out that their approaches complemented each other. We think that the first theme (safety and appreciation) together with a happy atmosphere, where students were smiling, chuckling, laughing, and joking (indicating positive emotions such as enjoyment and pleasure), set the stage for them to engage in within-solution PP in a safe and appreciating environment: to try different ideas and approaches without fearing consequences of failure.
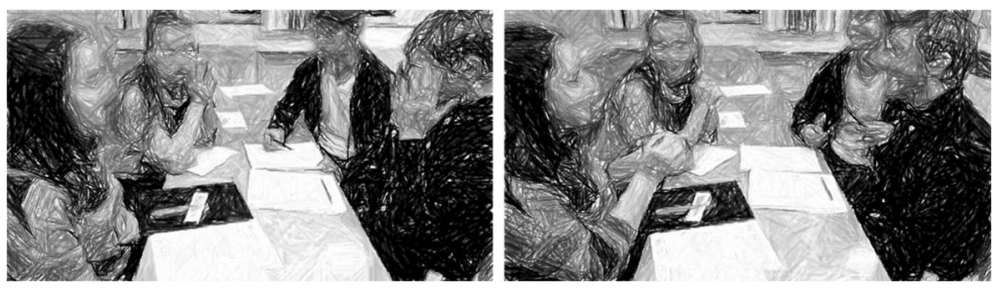

Fig. 4 Scenes in group work (Anna left, David right) 
Emotions

- Empathy and emotional support for

Self-efficacy

failure experience

- Happiness/relief that two persons approaches match

\section{Attitudes}

- Cautiousness with logical solutions ("dangerous")

- Cautiousness with unsupported assumptions

\section{Values}

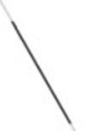

- Acceptance of failure in PS

- About problem solving (PS): Appreciation of confidence in PS, of systematics in PS, of not agreeing when not understanding, of another person's solution, and that two person's approaches match.

- About approaches: Appreciation of believable approaches, of logical approaches, of elegant approaches, of simple approaches, and of fast solutions.

\section{Emotions}

\section{Self-efficacy}

- Feeling safe through confirmation - Feeling professional, proud

- Feeling safe through correction

- Content-collaboration feels safe (to find a solution together).

- Relief to work together

- Collaboration is fun

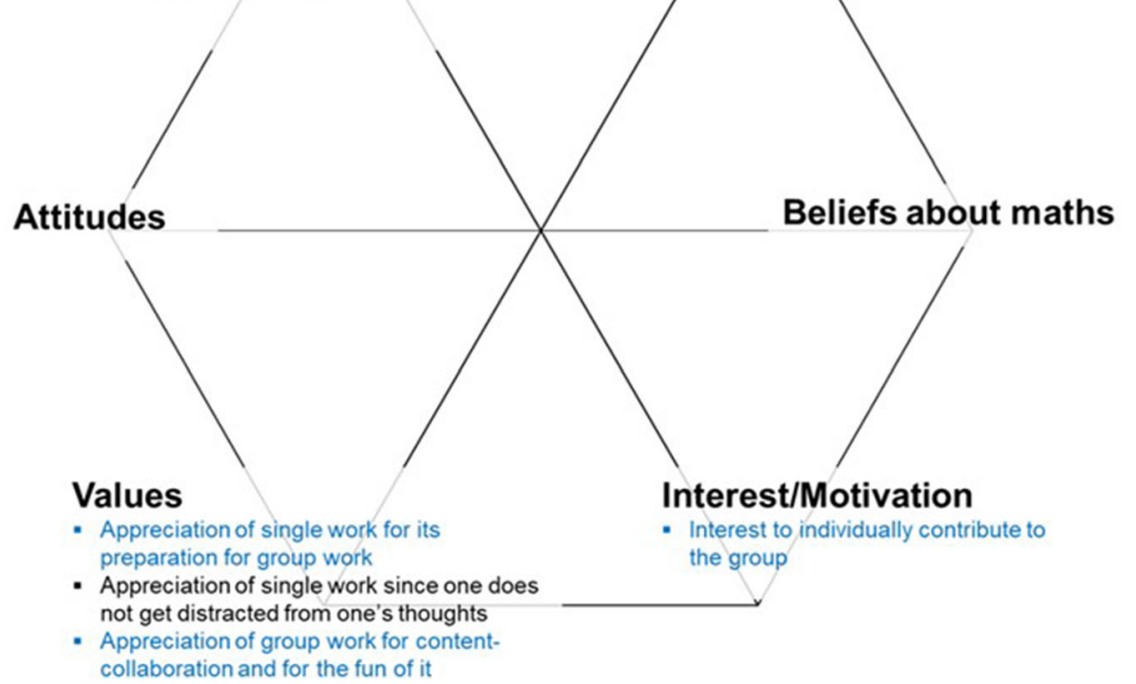

Fig. 5 Affective field during the group work (top) and after the 2nd meeting (bottom) (blue entries relate to Anna) 
Student reflection: At the end of the second meeting, the group reflected on their group work and collaboration (see Fig. 5). The students valued individual work for its purpose for the group work: getting the group to work, for the group to be able to come up with a solution, and for everyone to be able to contribute to the group. Anna stated, "I mean, to a certain extent you need to work alone to actually have something to say to the group." She also mentioned the risk that without individual work before group work, the group could be steered too easily by single persons. David valued individual work because there are no distractions. However, both Anna and Jakob mentioned that they feel little enjoyment (if at all) during the individual work, "the solitary path" (Jakob), and insecurity (Anna: "you're not sure about anything, you want confirmation"). The students related group work to enjoyment and to a feeling of safety: Either they got confirmation that their solutions from single work were correct or, if they made a mistake, they got corrected, which made them feel safe. Especially Anna emphasized the feeling of safety. They also valued everyone's contribution to the group. Yet, the students did not value group work only because of safety reasons: They also mentioned the benefit of having all the group members' ideas, which indicated the valence of content collaboration.

At the beginning of the third meeting, when the students recalled what they were working on in the second meeting, Anna said: "The dominos! (chuckling) (everyone chuckling, laughing) I was just explaining that to my friend. This felt so professional! (throwing her hair back with one hand) (everyone laughing)." Her utterance and chuckling indicate joy and pride, and that the collaborative work influenced her self-efficacy in a positive way. The group appeared to realize their collective efficacy, which "is developed when a group works" (Pantziara, 2016, p. 7).

Taking together the data from group work and student reflection in meeting 2 (snapshots in Fig. 5), we see that Anna's affective field - together with the group's - was positively affected: For example, her positive emotions of feeling happy and safe went along with increased interest in within-solution PP, which again went along with her feeling professional (selfefficacy). PP activities and attractions in the affective field went hand in hand.

\subsection{Third meeting: increased PP interest and belief change}

In the third meeting, the students worked on a problem (the city tour problem, see Supplementary Material 3), which was open and afforded within-solution PP in the way that the students were encouraged to find their own goals, perspectives, and problems to pursue. After their individual work, the students were to sit together. The teacher did not give an explicit instruction, neither was a particular problem solving focus given on the task sheet.

Group work: The group work in this meeting started with Anna asking the teacher for guidance. Right after the students sat down together as group, Anna asked:

Anna: (to the teacher) Do you want us to go through the other ones as well or should we just look at Melbourne, because that's the one-

Teacher: (cheerfully) Do whatever you want.

David: Yes.

Anna: Okay. 
Anna's initial question possibly reflected her belief that in mathematics, the teacher normally poses the question or tells what to investigate or her insecurity about how to proceed when there is no teacher guidance. The cheerful answer by the teacher indicated the teacher's aim not to be steering students' PP\&PS interests, in particular for the students to set focus themselves and develop their own PP interest. In turn, the students pursued different PP interests: for example, to inquire into the unsolvable instance (like Anna had suggested in the first place: to focus on the case of Melbourne) or to add a street in the map, which came along with enjoyment by Anna and Linda when thinking about how to rebuild the map of the city. Their PP activities were entangled with enjoyment and happiness. When it turned out that Linda had made a mistake in her solution and felt uncomfortable about it, Anna showed empathy and emotional support ("Yeah, I also, like when I did it, I was like: Oh I forgot this street! (...) And I'm like, damn it."), which was supported by David, and which encouraged Linda to stay in the game and to stay active in the group's inquiry activities. The group work went along for some minutes with different within-solution PP interests - the students playing around with different ideas about what to inquire into. Then, one student, Jakob, brought forward the idea to inquire into the number of roads at each intersection (vertex degree). The moment when Jakob brought forward this PP interest was - in our interpretation- the emotional peak of the collaborative PP\&PS in this meeting: All students got excited ("Oh!," "Mhhhhhh! Oh, yeah, yeah!," "Oh yeah, that's true, that's true!," "You are great!”). In our interpretation, the students had something like an Aha! moment, which come along with sudden certainty and affective responses (Liljedahl, 2013). David then gave an impulse to develop this idea even further by generalizing the PP focus to the parity of the number of roads at each intersection (even/odd), which was similar to the PP interest in meeting 2 (to generalize the problem to even/odd numbers). The PP interest to generalize the problem was again appreciated by the others and accordingly pursued in students' within-solution PP activities.

We identified two themes in students' group work - similar to the second meeting: The first theme again touched students' efforts to comfort each other when they reported failure experiences from individual work. They showed empathy and bonding efforts, which created a safe environment for the students. The second theme was students' inquiry drive together with PP interest. Even more than in the preceding meeting, students' group work was driven by their interest in within-solution PP (e.g., Cifarelli \& Sevim, 2015): The students changed perspectives, set their own goals, and pursued them. In doing so, they picked up each other's ideas and developed them further. This can be related to "problem posing-solving chains" (Cai $\&$ Cifarelli, 2005, p. 62), where the students pose new problems, pursue them, find new angles, etc. (see also Cifarelli \& Cai, 2005).

Student reflection: At the end of this meeting, the students reflected, among other things, about how the activities in the CMMs differed from their regular teaching at school, which hints at their beliefs about mathematics PS and the role of PP. All students in the group explained that and how their prior activities at school differed from those in the CMMs. Whereas prior school activities in their view appeared to be largely product focused, the students described that their activities in the CMMs also involved "finding things," "discovering the problem," or "creating our new problems," which may be related to within-solution PP in inquiry-based approaches (e.g., Cifarelli \& Cai, 2005; Cifarelli \& Sevim, 2015). This was related to their beliefs about mathematics: They perceived mathematics in the CMMS as "general, it's way more like continuous" (Anna) (see Fig. 6). 

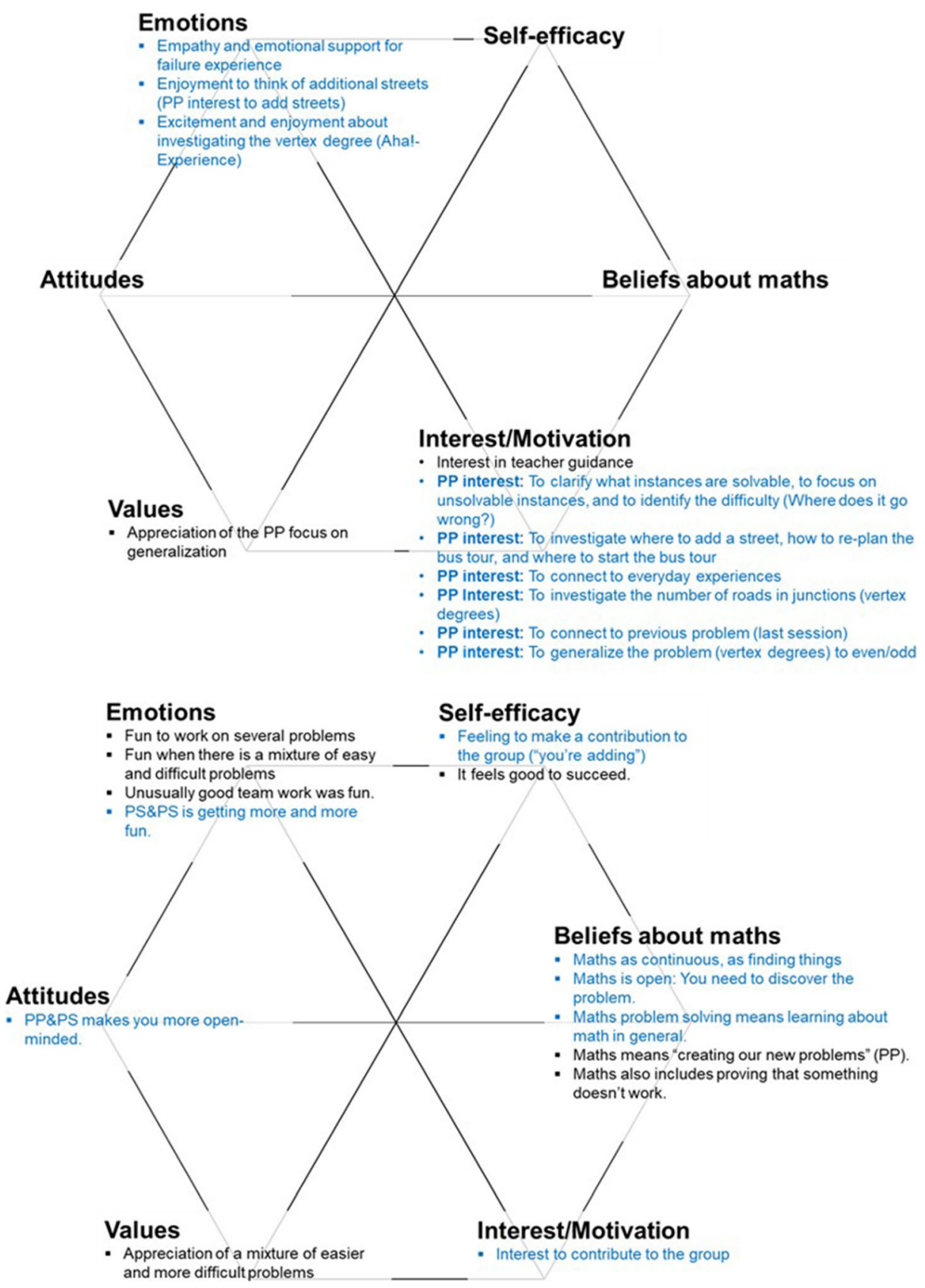

Fig. 6 Affective field during the group work (top) and after the 3rd meeting (bottom) (blue entries relate to Anna)

Further, the students emphasized their fun and enjoyment (e.g., "It's getting more and more fun."). The students got acquainted to working in an inquiry-based way and to pose problems. They further mentioned their feeling of each making an individual contribution ("adding" to the group), and this appeared to influence their self-efficacy positively. Together with their 
perception of "unusually good team work" (Jakob), this indicates their perceived collective efficacy (Pantziara, 2016).

Taking together the data from group work and student reflection in meeting 3 (snapshots in Fig. 6), we see that Anna's and the group's increased interest and engagement in withinsolution PP went along with positive emotions, such as fun, enjoyment, and excitement. These attractions to PP were entangled to the beliefs about mathematics: Whereas Anna had perceived mathematics as finding correct answers in her previous schooling (Fig. 3), she now described mathematics as finding and discovering things and as continuous (Fig. 6).

\subsection{Overall changes in the PP\&PS affective field}

We use data from the ninth meeting, where David and Anna reflected on how they developed during the CMMs, to illustrate the overall changes in Anna's affective field: In their descriptions, they explicitly opposed their views prior to the project (Fig. 3) to their current views (Fig. 7).

Changes in Anna's affective field are captured pointedly in her own words:

In the beginning it was really hard for me at least to let go of- 'cause I am always afraid of being wrong. But when you're trying to be creative you need to try different ways (pointing into different directions) and realize, okay that didn't work, next thing, that didn't work, and I mean just accepting that you were wrong, that's fine, and you move on, has been, like: What? I'm wrong! I'm so wrong! And then I get so stressed about it, instead of, okay, that's fine, move on. And that also comes from if you think that there is one way of doing it, and then you realize that that way isn't the right way, then you have nothing else to do, besides being scared that it didn't work. I don't know. But then,

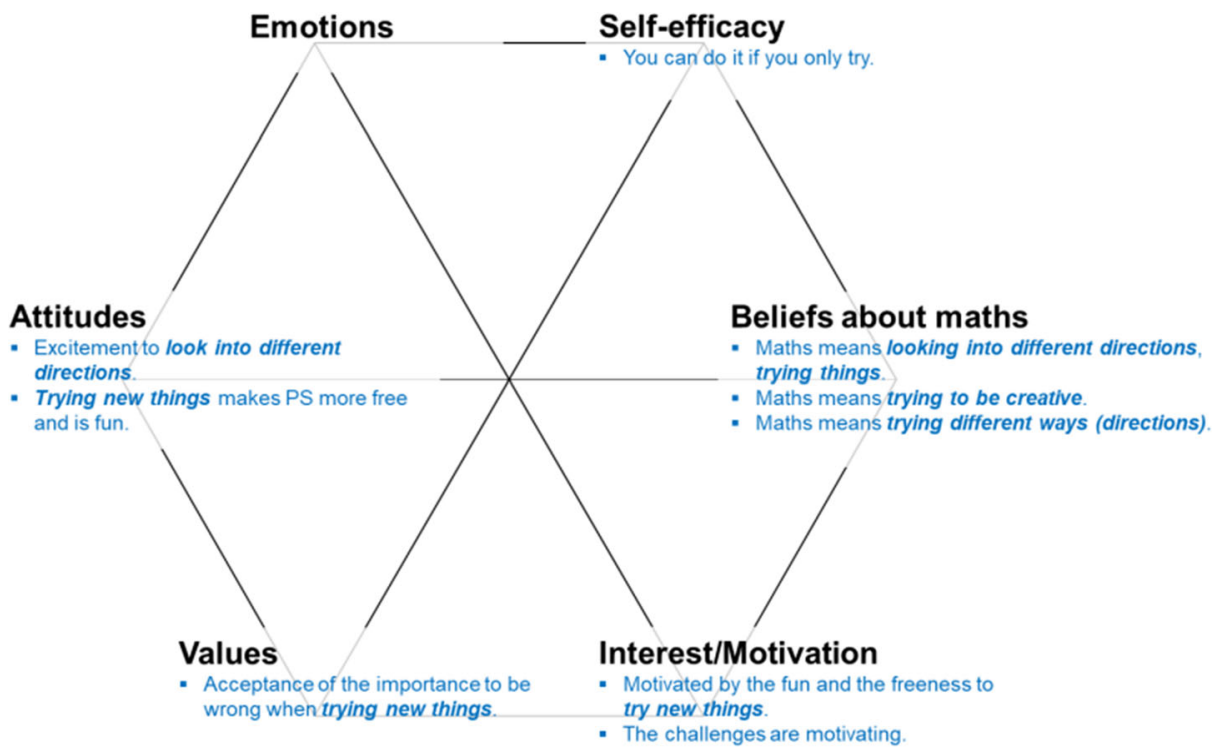

Fig. 7 Snapshot of the affective field that emerged in the project (blue entries relate to Anna) 
eventually, when you get to practice being wrong, and here (referring to the project) in other people's points of view there are other options, then it got easier and easier. But it was really hard 'cause it's so easy to hold on to this way of thinking, this way of feeling about it. And then, as it went along, it got better, 'cause you realize you could do it... if you only tried a little bit. It's so emotional... (chuckling).

Comparing Anna's affective field at this point in time to the one in the beginning of the project (Fig. 3), the positive evolvement is apparent. Anna emphasizes trying new things, trying different things, and looking into different directions-which all relates to within-solution PP. Many factors in her affective field have changed: Her attitudes shifted (from, e.g., "Mathematics is boring" to "Trying new things makes PS more free and is fun")- together with her beliefs about mathematics. This is again connected to her values (with a focus on outcomes initially, turning to valuing the process of trying new things and the acceptance of being wrong). Even though we refrain from making causal claims (about within-solution PP being causal for the changes in her affective field), we see that the increased interest in within-solution PP and positive dynamics in Anna's affective field co-occur.

\section{Discussion}

In this article, we proposed the notion of affective field to account for a person's various affective factors (emotions, attitudes, etc.) in their intraplay. In a case study, we investigated the affective field of Anna, an upper secondary school student, in its social and dynamic nature. We used data from an extracurricular, inquiry-oriented collaborative problem posing and problem solving (PP\&PS) program, which took place as a 1-year project with four upper secondary school students in Sweden (aged 16-18) and asked: In what ways does an affective field of a student engaging in PP\&PS evolve, and what may be explanations for this evolvement?

In short, we focused on Anna, who initially wanted to quit the collaborative meetings but became an active and positive participant. In line with similar studies that focused on affect as a broad domain rather than on particular constructs, we saw how many related affective factors were at stake, for example, emotions, attitudes, self-efficacy, interest, etc. Moreover, what we have come to characterize as an affective field, somewhat similar to a magnetic field with attractions and repulsions, proved to be dynamic - also in line with studies that were interested in the flux of affective factors rather than the influence on one construct on another.

Our case study illustrated the dynamics of Anna's affective field over the course of the school year. This concerned many affective factors involved in their intraplay. In the beginning, Anna's affective field was characterized by repulsions: negative emotions and low selfefficacy, which went along with beliefs of mathematics, for instance, as being a means to an end, with extrinsic motivation (doing mathematics to get grades), and negative attitudes ("maths is boring", "negative attitude" towards mathematics). However, over the course of the project, the students got increasingly interested to pose problems themselves, to connect problems, to generalize them, etc. Their attractions for PP went along with beliefs of mathematics as being continuous and open, with appreciation for generalization, with an open-minded attitude, and positive emotions such as fun and excitement. 
Over time, many factors have been driving forces for students' engagement in the PP\&PS process and for the evolvement of Anna's affective field. Our analyses illustrated how the group established a safe atmosphere through students' appreciation for and interest in each other's ideas and approaches, their positive handling of failure, and their efforts to comfort each other, to bond, and to show empathy. This set the stage for the students to get acquainted with inquiry-based PP\&PS and within-solution PP (Cifarelli \& Sevim, 2015), which the group developed an increased interest for over the course of the project. In their collaborative work, they set their own goals, modified the problems, and inquired into different directions. They spontaneously aimed for generalization of problems and for proving their discoveries and thus posed themselves new problems. The PP\&PS, along with increasingly positive affect, mostly seemed to be self-driving: The joy of solving a simple problem led them to pose a more difficult generalized problem. When they got stuck, they helped each other and aimed to combine their approaches. Affect and cognition seemed part and parcel of the same process. The PP experiences appeared to be highly affective for the students, they included Aha! moments (Liljedahl, 2013), and were related to belief change about mathematical PS.

In the reflective phases, the students articulated, among other things, how they felt. Anna repeatedly explained how her history of being used to one solution to mathematics problems (her "way of thinking" and "feeling" about it) had hindered her when she was confronted with the first problem in the inquiry-oriented meetings, which she was not able to solve. Her own explanation made sense to us: Failure decreased her motivation and self-efficacy.

Of course, the dynamics of Anna's affective field need to be regarded against the backdrop of the setting in which they took place. We think that the informal and voluntary nature of the ("out-of-regular-school") setting may have had a significant impact on the data, both in terms of the positive nature of Anna's affective field and in terms of the students' inclination to engage in PP while working on PS tasks. For the students, within-solution PP was different from regular schooling, where "[u]]sually, like, when you're solving a problem in the math book, it's like find the right answer, check it in facit [i.e., sample solution at the end of the book], be done with it" (Anna) and where "in the math book, in the end, $x$ equals a nice number. If it doesn't, something's wrong” (Anna). In the out-of-regular-school context, there was no grading, and the students did not even go to the same school classes, so that the meetings may have offered the opportunity for a "fresh start" which may have facilitated the establishment of new interests and norms.

It is a challenge to identify all affective factors involved in students' activities, educational science, and psychology that tend to focus on operational definitions and studying affective factors in isolation or small sets. Taking seriously a fluid ontology thus comes with methodological challenges (Sfard, 2008). Our case study illustrated how affective factors can be studied in an affective field (e.g., beliefs, emotions, interest, self-efficacy). Our analyses also illustrated that and how students' affective field was social: Affect was not separated between the persons but rather "contagious." The group dynamics were essential for Anna to overcome her anxiety, to feel she was contributing, and to increase her self-efficacy.

We think that future research could aim to study the social nature of the affective field more explicitly: To take the whole group's various affective factors as one affective field and to investigate interactions between affective factors within the group in their entanglement and intraplay. Yet, our project's original aim was not to investigate affective fields, and it was only in hindsight that we realized how affect was a crucial aspect in students' PP\&PS. Therefore, the students were not explicitly encouraged to reflect on their affect by the teacher-they only did so self-driven, with Anna being open and telling more about her feelings than others. We 
believe that future research with focus on groups' affective fields and even richer data will provide valuable findings on the contagion of affect within groups and also be able to investigate affective factors and their intraplay in more detail. Also, we feel that future research can further deepen analysis of students' affect. For example, Roth and Walshaw's (2019) analysis of pitch of voice could offer further indicators of affect. Also, the analysis of body movement (de Freitas et al., 2019), including the analysis of gestures, facial expressions, and eye movements, appears to offer valuable further insights. We think that micro-genetic multimodal data can be a rich basis to observe the multitude of affective factors during PP\&PS. Further, we recommend that future research could focus even more on the entanglement of PP and the affective field: In our study, PP emerged self-driven based on open mathematical problems, where the students inquired into different directions, tried new things, etc. Future projects could put even more emphasis on PP than ours and could help to understand the dynamics of affective fields connected to PP even deeper.

Yet, we think that our study did make a step to understand better the entanglement of affect and PP\&PS. Both the theorization of students' affective field and the empirical insights from the case study help to describe and explain the intricate relations between the various affective factors involved. We are well aware that through our choices, for instance, through the set of affective factors we coded in the data and through the definitions we made, we restricted our view (like with all choices) and maybe could have got further or deeper insights with other choices. Thus, we hope that our study can be a springboard for other researchers to take a holistic stance towards student affect and to develop our ideas further.

Funding Information Open Access funding provided by Projekt DEAL.

Open Access This article is licensed under a Creative Commons Attribution 4.0 International License, which permits use, sharing, adaptation, distribution and reproduction in any medium or format, as long as you give appropriate credit to the original author(s) and the source, provide a link to the Creative Commons licence, and indicate if changes were made. The images or other third party material in this article are included in the article's Creative Commons licence, unless indicated otherwise in a credit line to the material. If material is not included in the article's Creative Commons licence and your intended use is not permitted by statutory regulation or exceeds the permitted use, you will need to obtain permission directly from the copyright holder. To view a copy of this licence, visit http://creativecommons.org/licenses/by/4.0/.

\section{References}

Akkerman, D. M., Vulperhorst, J. P., \& Akkerman, S. F. (2019). A developmental extension to the multidimensional structure of interests. Journal of Educational Psychology, 112(1), 183-203.

Barad, K. (2007). Meeting the universe halfway: Quantum physics and the entanglement of matter and meaning. Durham, NC: Duke University Press.

Batchelor, S., Torbeyns, J., \& Verschaffel, L. (2019). Affect and mathematics in young children: An introduction. Educational Studies in Mathematics, 100(3), 201-209.

Bonotto, C., \& Dal Santo, L. (2015). On the relationship between problem posing, problem solving, and creativity in the primary school. In M. Singer, N. F. Ellerton, \& J. Cai (Eds.), Mathematical problem posing: From research to effective practice (pp. 103-124). New York, NY: Springer.

Brown, S. I., \& Walter, M. I. (1993). The art of problem posing. Philadelphia, PA: Franklin Institute Press.

Cai, J., \& Cifarelli, V. V. (2005). Exploring mathematical exploration: How two college students formulated and solved their own mathematical problems. Focus on Learning Problems in Mathematics, 27(3), 43-72.

Cai, J., Hwang, S., Jiang, C., \& Silber, S. (2015). Problem-posing research in mathematics education: Some answered and unanswered questions. In M. Singer, N. F. Ellerton, \& J. Cai (Eds.), Mathematical problem posing: From research to effective practice (pp. 3-34). New York, NY: Springer. 
Carmichael, C., Callingham, R., \& Watt, H. M. (2017). Classroom motivational environment influences on emotional and cognitive dimensions of student interest in mathematics. ZDM Mathematics Education, 49(3), 449-460.

Chang, K. E., Wu, L. J., Weng, S. E., \& Sung, Y. T. (2012). Embedding game-based problem-solving phase into problem-posing system for mathematics learning. Computers \& Education, 58(2), 775-786.

Chen, L., Van Dooren, W., \& Verschaffel, L. (2015). Enhancing the development of Chinese fifth-graders' problem-posing and problem-solving abilities, beliefs, and attitudes: A design experiment. In M. Singer, N. F. Ellerton, \& J. Cai (Eds.), Mathematical problem posing: From research to effective practice (pp. 309329). New York, NY: Springer.

Cifarelli, V. V., \& Cai, J. (2005). The evolution of mathematical explorations in open-ended problem solving situations. The Journal of Mathematical Behavior, 24(3/4), 302-324.

Cifarelli, V. V., \& Sevim, V. (2015). Problem posing as reformulation and sense-making within problem solving. In M. Singer, N. F. Ellerton, \& J. Cai (Eds.), Mathematical problem posing: From research to effective practice (pp. 177-194). New York, NY: Springer.

Cobb, P., Yackel, E., \& Wood, T. (1989). Young children's emotional acts while engaged in mathematical problem solving. In D. B. McLeod \& V. A. Adams (Eds.), Affect and mathematical problem solving: A new perspective (pp. 117-148). New York, NY: Springer.

de Freitas, E., Ferrara, F., \& Ferrari, G. (2019). The coordinated movements of collaborative mathematical tasks: The role of affect in transindividual sympathy. ZDM Mathematics Education, 51(2), 305-318.

Emotion. (n.d.). In Collins Dictionary. Retrieved from https://www.collinsdictionary. com/dictionary/english/emotion. Accessed 15 Dec 2019.

Grootenboer, P., \& Marshman, M. (2016). Mathematics, affect, and learning: Middle school students' beliefs and attitudes about mathematics education. Singapore: Springer.

Hannula, M. S. (2002). Attitude towards mathematics: Emotions, expectations and values. Educational Studies in Mathematics, 49(1), 25-46.

Hannula, M. S. (2006). Motivation in mathematics: Goals reflected in emotions. Educational Studies in Mathematics, 63(2), 165-178.

Hannula, M. S. (2011). The structure and dynamics of affect in mathematical thinking and learning. In M. Pytlak, E. Swoboda, \& T. Rowland (Eds.), Proceedings of CERME7 (pp. 34-60). Rzeszów, Poland: University of Rzesów.

Hannula, M. S. (2019). Young learners' mathematics-related affect: A commentary on concepts, methods, and developmental trends. Educational Studies in Mathematics, 100(3), 309-316.

Hansen, R., \& Hana, G. M. (2015). Problem posing from a modelling perspective. In M. Singer, N. F. Ellerton, \& J. Cai (Eds.), Mathematical problem posing: From research to effective practice (pp. 35-46). New York, NY: Springer.

Heyd-Metzuyanim, E., Lutovac, S., \& Kaasila, R. (2016). Identity. In G. A. Goldin et al. (Eds.), Attitudes, beliefs, motivation and identity in mathematics education: An overview of the field and future directions (pp. 14-17). Switzerland: Springer.

Horn, I. S. (2008). Turnaround students in high school mathematics: Constructing identities of competence through mathematical worlds. Mathematical Thinking and Learning, 10(3), 201-239.

Kaspersen, E., Pepin, B., \& Sikko, S. A. (2017). Measuring STEM students' mathematical identities. Educational Studies in Mathematics, 95(2), 163-179.

Kießwetter, K., \& Rehlich, H. (2005). Das Hamburger Modell der Begabungsforschung und Begabtenförderung im Bereich der Mathematik. [The Hamburg-model for the identification and promotion of mathematically talented students.] Der Mathematikunterricht, 51, 21-27.

Kilpatrick, J. (2016). Reformulating: Approaching mathematical problem solving as inquiry. In P. Felmer, E. Pehkonen, \& J. Kilpatrick (Eds.), Posing and solving mathematical problems: Advances and new perspectives (pp. 69-81). Switzerland: Springer.

Leikin, R. (2009). Exploring mathematical creativity using multiple solution tasks. In R. Leikin, A. Berman, \& B. Koichu (Eds.), Creativity in mathematics and the education of gifted students (pp. 129-145). Rotterdam, the Netherlands: Sense publishers.

Liljedahl, P. (2013). Illumination: An affective experience? ZDM Mathematics Education, 45, 253-265.

Lomas, G., Groetenboer, P., \& Attard, C. (2012). The affective domain in mathematics education. In B. Perry, T. Lowrie, T. Logan, A. MacDonald, \& J. Greenless (Eds.), Research in mathematics education in Australasia 2008-2001 (pp. 23-38). Amsterdam, the Netherlands: Sense publishers.

McLeod, D. B. (1992). Research on affect in mathematics education: A reconceptualization. In D. Grouws (Ed.), Handbook of research on mathematics teaching and learning (pp. 575-596). New York, NY: Macmillan.

Middleton, J. A., Jansen, A., \& Goldin, G. A. (2016). Motivation. In G. A. Goldin et al. (Eds.), Attitudes, beliefs, motivation and identity in mathematics education: An overview of the field and future directions (pp. 17-23). Switzerland: Springer. 
Motivation. (n.d.). In Duden. Retrieved from https:/www.duden.de/rechtschreibung/Motivation. Accessed 15 Dec 2019.

National Council of Teachers of Mathematics. (2000). Principles and standards for school mathematics. Reston, VA: NCTM.

Novotná, J. (2017). Problem solving through heuristic strategies as a way to make all pupils engaged. In B. Kaur, W. K. Ho, T. L. Toh, \& B. H. Choy (Eds.), Proceedings of the 41st Conference of the International Group for the Psychology of Mathematics Education (vol. 1, pp. 29-44). Singapore: PME.

O'Keefe, P. A., Horberg, E. J., \& Plante, I. (2017). The multifaceted role of interest in motivation and engagement. In P. A. O’Keefe \& J. M. Harackiewicz (Eds.), The science of interest (pp. 49-67). New York, NY: Springer.

Pajares, F., \& Miller, M. D. (1994). Role of self-efficacy and self-concept beliefs in mathematical problem solving: A path analysis. Journal of Educational Psychology, 86(2), 193-203.

Pantziara, M. (2016). Student self-efficacy beliefs. In G. A. Goldin et al. (Eds.), Attitudes, beliefs, motivation and identity in mathematics education: An overview of the field and future directions (pp. 7-11). Switzerland: Springer.

Philipp, R. A. (2007). Mathematics teachers' beliefs and affect. In F. K. Lester (Ed.), Second handbook of research on mathematics teaching and learning (pp. 257-315). Charlotte, NC: Information Age Publishing.

Pirie, S. E. B., \& Kieran, T. (1994). Growth in mathematical understanding: How can we characterize it and how can we represent it? Educational Studies in Mathematics, 26(2/3), 165-190.

Renninger, K. A. (2009). Interest and identity development in instruction: An inductive model. Educational Psychologist, 44(2), 105-118.

Renninger, K. A., \& Hidi, S. (2016). The power of interest for motivation and engagement. New York, NY: Routledge.

Rokeach, M. (1973). The nature of human values. New York, NY: The Free Press.

Roth, W. M., \& Walshaw, M. (2019). Affect and emotions in mathematics education: Toward a holistic psychology of mathematics education. Educational Studies in Mathematics, 102, 111-125.

Savelsbergh, E. R., Prins, G. T., Rietbergen, C., Fechner, S., Vaessen, B. E., Draijer, J. M., \& Bakker, A. (2016). Effects of innovative science and mathematics teaching on student attitudes and achievement: A metaanalytic study. Educational Research Review, 19, 158-172.

Schoenfeld, A. H. (1985). Mathematical problem solving. Orlando, FL: Academic.

Schukajlow, S., Leiss, D., Pekrun, R., Blum, W., Müller, M., \& Messner, R. (2012). Teaching methods for modelling problems and students' task-specific enjoyment, value, interest and self-efficacy expectations. Educational Studies in Mathematics, 79(2), 215-237.

Schukajlow, S., Rakoczy, K., \& Pekrun, R. (2017). Emotions and motivation in mathematics education: Theoretical considerations and empirical contributions. ZDM, 49(3), 307-322.

Sfard, A. (2008). Thinking as communicating. Human development, the growth of discourses, and mathematizing. Cambridge, UK: Cambridge University Press.

Silver, E. A. (1994). On mathematical problem posing. For the Learning of Mathematics, 14(1), 19-28.

Silver, E. A., \& Cai, J. (1996). An analysis of arithmetic problem posing by middle school students. Journal for Research in Mathematics Education, 27(5), 521-539.

Singer, F. M., \& Moscovici, H. (2008). Teaching and learning cycles in a constructivist approach to instruction. Teaching and Teacher Education, 24(6), 1613-1634.

Singer, F. M., Ellerton, N., \& Cai, J. (2013). Problem-posing research in mathematics education: New questions and directions. Educational Studies in Mathematics, 83(1), 1-7.

Starko, A. J. (2010). Creativity in the classroom. Schools of curious delight. New York, NY: Routledge.

Wigfield, A., \& Cambria, J. (2010). Students' achievement values, goal orientations, and interest: Definitions, development, and relations to achievement outcomes. Developmental Review, 30, 1-35.

Zan, R., Brown, L., Evans, J., \& Hannula, M. S. (2006). Affect in mathematics education: An introduction. Educational Studies in Mathematics, 63(2), 113-121.

Publisher's note Springer Nature remains neutral with regard to jurisdictional claims in published maps and institutional affiliations. 